\title{
Technification of Knowledge and Knowledge as Technology: the University as the Verse to Come
}

\author{
Samrat Sengupta \\ Assistant Professor and Head, Department of English, Sammilani Mahavidyalaya. \\ Email: samrat19802003@yahoo.co.in
}

\begin{abstract}
:
In the very act of pronouncing the word Uni-Versity the uni- in university motivates the versity the becoming of the verse as memory - as the act of foregrounding knowledge and its continuity in time - the ontology as well as epistemology of culture and society. But at the same time the uni- is in conflict with the verse making - the versity. This double gesture produces the space of the university as an impossible, contingent and precarious space of learning. So the outside of the university is connected - hyperlinked to its inside space. If the university is made into a decided space of providing information and skill then it ceases to be a university. The erosion of liberal humanist university gradually being overcome by technological skill based universities announces the end of university. This paper shall talk about the transformative potentialities of the verse the possibilities of unexpected turn that cannot be overcome by any technification and enframing. I would discuss university as a dialectics of desire for unification on one hand and the dynamic creative potentiality on the other that ceaselessly challenges and overcomes that unitary impulse. The idea of the University here has been discussed through the critical theoretical interventions in Jacques Derrida and Bernard Stiegler.
\end{abstract}

Keywords: Artifactuality, Stupidity, University, Information-Power, Enframing

The word University has close and cognate relationship with allied words such as universe and universal. Universe becomes a noun meaning "the whole world, the cosmos, the totality of things" derived from Latin universum in around 1580 s as the noun form of the adjective universus. Universus means "relating to one", or more literally "turned into one". It came from unus (from pie root oi-no meaning "one" or "unique") and versus, the past participle of vertere meaning "to turn, turn back, be turned; convert, transform, translate; be changed" (from pie root wer meaning "to turn, bend"). While pronouncing the word university and its deep inalienable relationship with the idea of the "universal" we often ignore the possibility of the paleonymic recurrence of its earlier traces. In the process of ascribing oneness to the hyphenated difference between the uni and the versus, the undecidable fuzzy horizon of the 'turn' - the precarious movement from ignorance to understanding and the versification of the world into meaning is often forgotten.

(C) AesthetixMS 2020. This Open Access article is published under a Creative Commons Attribution Non-Commercial 4.o International License (http://creativecommons.org/licenses/by-nc/4.o/), which permits non-commercial re-use, distribution, and reproduction in any medium, provided the original work is properly cited. For citation use the DOI. For commercial re-use, please contact editor@rupkatha.com. 
The pie root wer also produces the word 'verse' and has the essence of ploughing, thereby connecting the creation of lines in poetry with the turning of the field. The labour of the turn is imbued with the horizon of expectation of new harvest - of creation that is unforeseeable. Verse in ancient civilization was used as an aid to memory. In that sense it has a mechanical aspect of recording - a certain technification of knowledge - a cult of preservation and a creation of an apparatus of security. Verse therefore also employed a frame to knowledge, particularly in the age of oral transmission. The act of enframing (Heidegger 2008, pp. 311-340) in the idea of verse is constantly in tussle with the idea of turning - the labour of movement towards knowing. It is comparable to the philosophical struggle within the invisibilized and forgotten hyphen in the word Uni-versal or Uni-versity. The "oneness" in "uni" may determine the "verse", but it may also get challenged by the indeterminate and the creative possibility of "verse" - its poetic irreverence to the universal. This article briefly comments on the challenges of different forms of enframing that encloses and confines knowledge - that secures it with the technical aid and spatial limits, thereby giving rise to the idea of University as a place of preservation, determination, securing and hegemonization of knowledge. The economy of digital aid to knowledge - its virtual determination of factuality or what we may call in terms of Jacques Derrida artifactuality or actuvirtuality, (Derrida and Stiegler 2002, p. 3) is the most recent form of securing and manufacturing knowledge. The tension between securing and preservation of knowledge on one hand and precarity of knowledge as new turn, that overcomes the structural confinement, achieves a new form in the digital world. It creates a new form of stupidity by alienating the unknown and impossible turns to the process of knowing. However the failure of determination of truth - the inadequacies of boundaries in the digital world of knowledge creates new philosophical possibilities of rethinking the University beyond physical structures and limits. It can be thought in terms of the hyphen between the uni and the verse - the tussle and indeterminacy between unification and regimentation of knowledge and unexplored possibility of verse that is to come - the new turn.

\section{The University as Verse to Come:}

In the word "Uni-Versity" we must remember the hyphenation that disappears and dissolves in the act of communion. University is a space of potentialities (Agamben 1999, pp. 177-184). It is an incomplete place of becoming. Its idea of space is not determined beforehand and has to be worked out though the entangled relationship between teacher, student and repositories of existing knowledge and artefacts. The emptiness of space - the choric possibility of unbecoming and collapse of the existing ideas of truth haunts the place we call university. The becoming of the space is always incomplete and it invites completion. It goes beyond all metaphysical foregrounding and enframing. It looks into the past to invent new temporalities, just as it looks into its outside for incessant radical reconstruction. The uni- in university motivates the versity the becoming of the verse as memory - the act of foregrounding knowledge and its continuity in time - the ontology as well as epistemology of culture and society. But at the same time the uni- is in conflict with the verse making - the versity. This double gesture produces the space of the university as an impossible, contingent and precarious space of learning. So the outside of the university is connected - hyperlinked to its inside space, and so a university can never be a complete and finished product (the way we understand a product in liberal consumerist democracy). A University is never apolitical and is a resource of ideological determinations. Authorities want to use university as a space for establishing its hegemony. Louis Althusser describes it as a part of the Ideological State Apparatuses (Althusser 1971, pp. 121-176). In the present context the University subscribes to the neo-liberal ideology and is attempted to be made into a decided space of providing information and skill. In that case it challenges the idea of 
university as a space of distributing and disseminating knowledge. The erosion of liberal humanist university gradually being overcome by technological skill based universities announces an apparent end of the idea of University. But the University can't die as the conflict between determination of truth and undecidability at the heart of producing knowledge cannot be dissolved. It rather returns in a much more challenging form in the digital age. The idea of a University becomes spectralized (as apparently dead but resurrected as an invisible presence) along with its internal struggle for hegemony and politics of truth. University is here referred as a genre than any individual institution. The moment university dies it is reborn into other forms. Neither the desire for oneness, nor the failure to achieve it can end. The transformative potentialities of the verse - the possibilities of unexpected turn cannot be overcome by any technification and enframing. University remains as a form of writing of truth and knowledge $-\mathrm{a}$ process of meaning making. In this way it will be struggling against the assumed universality and universalism of academic institutions as spaces of doing what should be done.

Digital technology in this context ushers a new turn to the idea of knowledge. It radically shifts our notions of truth and understanding as it makes it evident and conspicuous that truth could be manipulated, manufactured and produced through editing and virtualizing. It collapses the necessity of truth and opens up an age of not only post-truth but also post-reason. The measurement of cause-effect relationship in the method of reasoning can no longer maintain its stronghold since this relationship and its resultant affect could be manufactured digitally by recontexualization and production of new reconnections between facts and information. In this context then the function of humanities to contest the dominant forms of knowledge, to critique them becomes redundant, as much as the necessity of knowledge itself. So we are heading towards an age of post-humanities.

\section{Truth in the age of Information-Power:}

Information becomes the new mode of power that can be used effectively for the purpose of smooth functioning of the system of global capitalism. In another article the present author writes

The automatization of information produces the informatics which when transmitted via teletechnologies become telematics. Speed, usability and transmission to real time are features that produce the new order of things the new truth regime. It transforms the spectrality of the past into presentness by capturing, archiving and transmitting it through information networks. The archive is a repository of information that becomes a mechanism of controlling and determining the present world order... This is the paradigm of information power displacing and also collaborating with biopower where the subject is a rights-bearing individual and where rights are defined in terms of information about his multiple identity cards-his ethnicity, nationality, race, language, habits, profession, etc. (Sengupta 2016, pp. 143-158)

However this new technology of digitalization and its mode of power act as a pharmakon (both poison and medicine) to thinking. It becomes a non-space where determinacy and accuracy gives way to radical indeterminacy and anxiety of inaccuracy. So this opens up a space for thinking. Bernard Stiegler in his book States of Shock: Knowledge and Stupidity (2015) talks about this pharmacological truth of any form of writing technology. On one hand one attempts to write reasonably and universally what is true and on the other hand in this process of producing true knowledge an element of non-knowledge or stupidity haunts. This elemental stupidity at the heart of human reason is the cause of the quest for new knowledge. While all practices of knowledge after enlightenment tries to profess the true form of reasoning, in the process of doing 
so they fetishize reason and interrupts its smooth functioning. The same practice becomes more acute and astute in digital technology as it wants to form as well as regulate information. It collapses the myth of truth as pre-given and untamperable as it engages with processing information as truth, giving it reality-effect/truth-effect for smooth functioning of the global capitalist regime of power. Therefore it collapses the notion of evidential truth and opens up the space for analytical reasoning. It calls for the ushering in of a digital counter-public to emerge who will incessantly arguing for a democracy-to-come, against the digital determination of information as knowing. Here is where the idea of the future university comes.

While keeping in mind the necessity of spatial boundaries of knowledge production, the sense of a structure and belonging, we must also recognize the spectral presence of an outside. The outside becomes more and more spectral in the form of whatever goes beyond usability of the information-power. The neo-liberal universities are made skill based and spaces of producing excellence instead of knowledge (Readings 1996, pp. 1-43). It attempts to measure the work and productivity of a student, scholar and professor in terms of more and more informative and calculative precision. Therefore the purpose of university as a space for retention and protention, of preservation of memory and its projection to the future as anticipation of new significance, fails (Derrida 2002, p. 12). The neo-liberal Universities wants to convert the knowledge of past, present and future into archives of information thereby reducing academic work to usability for maintaining the stability of global capitalist apparatus.

In States of Shock Stiegler talks about how knowledge is produced through a generational debate over the nature of truth. The digitalization of truth destroys such possibility of transindividuation as the authority and hegemony over dominant forms of knowledge passes from human communities to digital networks and teletechnological devices. Therefore -

the technological becoming of knowledge has disrupted the conditions of the transindividuation of that disciplinary knowledge that is reputedly 'rational', that is, the result of critique deriving from logical, public disputation. And this disruption has interfered with the critical faculty itself as the capacity to distinguish between knowledge, opinion and dogma. (Stiegler 2015, p. 129)

The paradigm of information-power radically reduces the notion of the individual as information bubble - a fluid mass of information connected to his/her social position - the racial, ethnic, national, linguistic, class, caste, gender or sexual identity or his/her social desire. The intersubjective and transindividual potentiality of the individual is thus corrupted in the selffashioning of information-power. The idea of the individual gradually becomes mediated by information and not by knowledge. The current academic, intellectual, and political practices are shaped by such a notion. The intersectional spaces between identities are either never foregrounded in this form of power or are being used to break down the political collective. In short there cannot be any dialogues between identities. There cannot be any political collective of minorities or marginalized according to information-power which assumes identities to be constructed and determined by data and information, immutably connected to their respective boundaries. The political sphere in this situation becomes incessantly a space for bullshit without liability and commitment. The dribble over correctness and who is more subjugated than the other becomes the occasion for capitalism to destroy politics and convert it into either museumized spaces of nostalgia and romanticism, or collection of information to be addressed and pacified by power - into a form of industrialized memory (Stiegler 2009). Resistance in this structure is seen as a part of endless negotiations in the political rational order, only taking the guise of the irrational temporarily. The poetic horizon of undecidability in such structure of 
governance suffers a slow death while humanities as an academic discipline meet a supposed end. The gradual privatization of academic spaces, reduction of knowledge into useable information is only but a part of this larger design. The hyperspecialization of academic language and distancing of the academicians from people and their politics in general are also a consequence and cause of such a techno-ideational paradigm. After the post-7os academic politics David Harvey expresses his suspicion -

the cultural transformations in urban life that subsequently occurred, as naked capital masked itself in commodity fetishism, niche marketing, and urban cultural consumerism, played a far from innocent role in the post-'68 pacification (for instance, the newspaper Liberation, which was founded by Jean-Paul Sartre and others, gradually shifted from the mid '7os to become culturally radical and individualistic but politically lukewarm, if not antagonistic to serious left and collectivist politics). (Harvey 2012, p. xi)

\section{Technology as a Zone of Conflict:}

Technological innovation and its resultant mode of writing always give birth to a zone of conflict. The ideological rift is between tendencies to concretize - to enframe - to produce newer selffashioning and its counter tendencies to question the existent processes of concretization, to motivate new relations of production vaporizing the old. The shift from orality to writing motivated by invention of the printing technology caused the written words to become the new mode of preserving the truth - of preserving memory and knowledge and reconfiguring the relationship between them. This shift is both technological and ideological. It can be called technoideational. It grounds the logical as well as opens up new possibilities of displacing that form of reason. There is an inalienable relationship between the processes of concretization of meaning and its failure. University is a non-space where such drama is played out. It is a nonspace pregnant with the possibility of the 'event' which would eventually produce the idea of the space anew. It is a non-space of perpetual becoming. In words of Agamben it can be defined in terms of potentialities to be (Agemben 1999, p. 183). Therefore it is a site of philosophical reckoning. The strife is also between knowledge and memory - between experience and truth, between reality and its representation. One side of it tries to foreclose the other, but at the same time also fails such foreclosure. In the Anglo-European context in Nineteenth century a certain idea of 'public' developed out of the technology of writing. The idea of a collective was thus reframed from a community of story-telling to a community of experiences (that could be shared and universalized in terms of writing). Explanation and logical reasoning in terms of concrete cause-effect relationship is the mode of such transformation. The ideological underpinning is that we can grasp reality in written sign. So explanation becomes a mode of producing knowledge in terms of the rationalizing experience. That is the legacy of the enlightenment which wants to shut out the inexplicable and the non-rational and write down truth in the form of concrete rational knowledge. History is possible by keeping out the irrational as madness. Reason then becomes the paradigm of knowing and experiencing the truth and the ideological benchmark of the technique of writing. The nation-states are also framed likewise in terms of shared history and explanation of events in history in the form of writing, as repository of knowledge. This is where memory meets knowledge and the psychical individuation meets the social and the collective individuation. But we have discussed that such concretization is not completely possible, and the nature of history is a zone of conflict marked by counter-explanations and arguments. The concept of the 'real' is always a site of stupidity and violence. There has been a major shift in this technoideational paradigm with the invention of recording technology of sights and sounds in the Twentieth century. It also inaugurates a new concept of representation and knowledge. It claims 
to replicate the real, the concrete and the presence with much proximity than ever before. The hyperactive reason moves from the paradigm of analytical to the empirical. The notion of scientific precision borders on bureaucratic rationalism strengthening the enframing. Simultanously there have been a rise in critical philosophy and poetry that encourages a radical disbelief in sign. Reality becomes unfathomable in the age of excessive visibility, conflicting movement of visual signs, causing the trauma of disbelief as well as philosophical enquiry.

In the world of twenty first century digital technology virtual space itself can become similarly an undecidable non-space of encounter. The pharmakon of digital technology brings the beyond of a regimented and determinate space of knowledge into the world of learning and makes the entire world a possible university. The university that is to come through this conflict between truth and non-truth is motivated towards a verse to come - a new turn inaugurated through digital precariousness of meaning and truth. This verse to come is a remembrance - a turn of memory (wer - "to turn, bend") that is beyond the control of digitization, though it happens through it. It opens up the question of an emergent digital counterpublic who are collectively pushing the authority of technical precision and information to its limit and exposes its lack. This act itself is techno-logical and shapes the idea of the university towards its radical unbecoming. The end of public authority of Universities as a seat of professing truth and its appropriation into technical digital apparatus of information-power is also a beginning. It opens up the thinking of the philosophical question of reality and truth and also forces the University towards its outside through indeterminate networks of thought.

\section{References:}

Agamben, Giorgio. (1999). "On Potentialities” In Potentialities: Collected Essays in Philosophy (pp. 177-184). Stanford University Press.

Althusser, Louis. (1971). Ideology and ideological state apparatuses. In L. Althusser (Ed.), Lenin and Philosophy and Other Essays (pp. 121-176). Monthly Review Press.

Derrida, Jacques and Bernard Stiegler. (2002). Echographies of Television: Filmed Interviews. Polity Press.

Harvey, David. (2012). Rebel Cities: From the Right to the Cityto the Urban Revolution. Verso.

Heidegger, Martin. (2008). “The Question Concerning Technology” In David Farell Krell (Eds.), Martin Heidegger: Basic Writings (pp. 311-340). Harperperinneal.

Online Etymological Dictionary (n.d.). Universe, University, and Verse. In Online Etymological Dictionary. Retrieved January 4, 2020, from https://www.etymonline.com/

Readings, Bill (1996). The University in Ruins. Harvard University Press.

Sengupta, Samrat. (2016). "Information-power: Teletechnology and the Ethics of Human Animal Difference" In Makarand R. Paranjape and Debashish Banerji (Eds.) Critical Posthumanism and Planetary Futures. (pp. 143-158). Springer India.

Stiegler, Bernard. (2009). Technics and Time 2: Disorientation. Stanford University Press.

Stiegler, Bernard. (2015). States of Shock: Knowledge and Stupidity. Polity Press.

Dr. Samrat Sengupta is Assistant Professor and Head of the Dept. of English at Sammilani Mahavidyalaya under University of Calcutta. His research interests include Experimental Bengali Literature. Gender studies, Post-structuralism, Memory Studies and Posthumanism. He has 
7 | Technification of Knowledge and Knowledge as Technology: the University as the Verse to Come

recently co-edited a special issue of the international journal Sanglap on "Caste in Humanities". His first Bengali monograph on Pratibader Pathokrom (Syllabi of Resistance) will be published in 2020. His co-edited volume on Bengali experimental writer Nabarun Bhattacharya titled Nabarun Bhattacharya: Aesthetics and Politics in a World after Ethics is forthcoming this year from Bloomsbury. 